Article

\title{
An Iterative Methodology for Model Complexity Reduction in Residential Building Simulation
}

\author{
Mattia De Rosa ${ }^{1,2, *}\left(\mathbb{D}\right.$, , Marcus Brennenstuhl ${ }^{3}$, Carlos Andrade Cabrera ${ }^{1}$, Ursula Eicker ${ }^{3}$ and \\ Donal P. Finn 1,2 (iD \\ 1 School of Mechanical and Materials Engineering, University College Dublin, Belfield, Dublin 4, Ireland; \\ carlos.andradecabrera@ucdconnect.ie (C.A.C.); donal.finn@ucd.ie (D.P.F.) \\ 2 UCD Energy Institute, University College Dublin. Belfield, Dublin 4, Ireland \\ 3 Centre for Sustainable Energy Technology, University of Applied Science Stuttgart, \\ 70174 Stuttgart, Germany; marcus.brennenstuhl@hft-stuttgart.de (M.B.); ursula.eicker@hft-stuttgart.de (U.E.) \\ * Correspondence: mattia.derosa@ucd.ie or mattia.derosa@outlook.com
}

Received: 8 March 2019; Accepted: 20 June 2019; Published: 25 June 2019

check for updates

\begin{abstract}
The present paper introduces an iterative methodology to progressively reduce building simulation model complexity with the aim of identifying potential trade-offs between computational requirements (i.e., model complexity) and energy estimation accuracy. Different levels of model complexity are analysed, from commercial building energy simulation tools to low order calibrated thermal networks models. Experimental data from a residential building in Germany were collected and used to validate two detailed white-box models and a simplified white-box model. The validation process was performed in terms of internal temperature profiles and building thermal energy demand predictions. Synthetic profiles were generated from the validated models and used for calibrating high order models. A reduction (trimming) procedure was applied to reduce the model complexity using an energy performance criterion prior to model trimming. The proposed methodology has the advantage of keeping the physical structure of the original RC model, thus enabling the use of the trimmed lumped parameter building model for other applications. The analysis showed that it is possible to reduce the model complexity by half, while keeping the accuracy above $90 \%$ for the targeted building.
\end{abstract}

Keywords: building simulation; model calibration; reduced models; smart grids; energy performance forecasting

\section{Introduction}

Buildings account for about $36 \%$ of the total primary energy consumption and nearly $40 \%$ of total carbon emissions worldwide, with an increase trend of $1 \%$ per year [1]. Consequently, various legislation initiatives have been put in place at national and international levels to pursue a low-carbon economy by fostering energy efficiency measures and the deployment of renewable energy systems in buildings [2,3].

The efforts towards the so-called net zero energy buildings (NZEB) require buildings to be prosumer, a neologism built by the portmanteau of producer and consumer, which highlights the duality of both producing and consuming energy. Such local and widespread generation, which includes the deployment of renewable energy systems, result in an increase of the variability at the demand side level [4,5]. This aspect represents a challenge for the power grid, since it may lead to grid congestion and atypical power flows, which would stress the stability of the transmission and distribution grids. Increasing the grid flexibility is therefore paramount in order to pursue the NZEB goal [6]. 
Generally, grid flexibility is provided by the supply side, by using dedicated conventional power plants or storage to balance mis-matches in electricity production and demand [7]. On the other hand, Smart Energy Networks (or Smart Grids) require demand, and local and central production to be controlled to achieve the grid stabilisation [8]. The so-called Demand Side Management (DSM) is defined as the capability of the demand side to change its energy usage by reducing, increasing or rescheduling its consumption [7]. Among others, Demand Response (DR) is a particular DSM strategy which consists of a change in the user electrical energy profile following a request from the system operator, or in response to market price signal [9]. Unlocking the DSM/DR technical potential, determined by the energy flexibility available at the user level, can be a complex and multidisciplinary task which involves technological, modelling, market and policy aspects $[7,10,11]$.

Therefore, being able to forecast building electrical and thermal loads is of vital importance to grid operators, aggregators and building energy management systems. These forecasts could offer comprehensive knowledge on the DR potential in different building types and may be able to offer useful insights to the power system, as highlighted by the IEA [4]. In this context, physically-based (i.e., white box) building energy models (PB/BEM) [12] are paramount to provide urban planners, local administrations and energy providers with tools capable to analyse building energy consumption at aggregated levels. However, the direct use of aggregated PB/BEMS can prove to be computationally demanding, as mentioned in Davila et al. [13]. An alternative to PE/BEMS modelling may be represented by the development of numerically efficient simplified building energy models representative of the residential stock under study [14]. Simplified building energy models are capable of reducing the required computation time for energy simulations at scales suitable from an aggregation perspective, as demonstrated by Kim et al. [15] and Good et al. [16].

Among others, lumped parameter building energy models are one of the recognised techniques capable of meeting the target of reducing the computational cost while achieving a good grade of accuracy $[17,18]$. These models, also called RC building thermal networks, are based on the electrical analogy method, in which electric resistances and capacitances model the thermal resistance and capacitance of material layers. High order RC models with physically-based parameters can be considered as simplified white-box models [19]. Considering a system divided in $N$ elements, the heat balance at each thermal node $n$ is modelled as a first-order differential equation, taking the form:

$$
C_{n} \frac{d T_{n}}{d \tau}=\sum_{\forall i \in N} \frac{T_{i}-T_{n}}{R_{i}}+\Phi_{n}
$$

where $C_{n}$ and $T_{n}$ are the thermal capacitance and temperature of the component $n, R_{i}$ is the thermal resistance between elements $i$ and $n$, and $\Phi_{n}$ is the sum of all the heat fluxes applied to the node $n$. Different level of complexity can be achieved by increasing or reducing the number of nodes (i.e., equations), which determines the order of the model and the number of parameters required. For instance, Zhou et al. [20] developed a simplified RC model, consisting of eight resistances and seven thermal capacitances (i.e., 8R7C) for control purposes, which showed good agreement with the experimental results.

Similarly, Berthou et al. [21] used four different models (4R3C, 6R2C, 6R3C and 7R3C) to predict heating and cooling demands as well as the indoor air temperature of a ten-storey office building in Paris, France. Estimation errors below 15\% were shown by all models considered. De Rosa et al. [19] developed a 23R7C to predict the building energy consumption for heating and cooling. The model implements a single node capacitance for the building envelope and takes into account the different wall orientations when computing the absorbed solar radiations (direct, diffuse and reflected). The comparison with synthetic data from commercial software (i.e., TRNSYS and Energy Plus) showed deviations below $9 \%$. The model was then extended by increasing the model order to investigate the influence of the wall discretisation on the model accuracy [22].

An interesting aspect of RC models is that they provide a physically-based model whose parameters can also be calibrated against metered (or synthetic) data with the aim of improving 
their accuracy. Numerically, the automated calibration problem consists of identifying building model parameters which minimise the error between the model predictions and synthetic or metered building data [23]. The minimisation problem is typically non-linear and non-convex given the nature of the parameters being estimated (e.g., $1 / C_{n} R_{i}$ ). The resulting model keeps the original physically-based structure, but the calibrated parameters do not reflect the thermo-physical characteristics of the building. In other words, after the calibration, it will not be possible to get back to the real physical characteristics of the building starting from the calibrated parameters. Consequently, these calibrated models can also be considered as grey-box models.

Generally, grey-box models have the advantage of keeping a physical-based structure while reducing the level of information details about the building, since only rough initial guesses are needed as starting point for the calibration procedure [24]. Moreover, grey-box models typically require shorter periods of data than black-box models for their calibration [25]. This semi-physical interpretation of grey-box models, together with the reduced dataset required, makes them suitable for model order reduction procedures aimed at adjusting their complexity to the specific application required, such performance assessments and smart controls [26]. In particular, these models can be used to calibrate a cluster of retrofitted building models simultaneously, as shown by Andrade-Cabrera et al. [27], who performed a model order reduction in order to increase the computational performance of such models. However, reducing the complexity of the retrofitted models by using automated model reduction methods, such as balanced truncation [28], may lead to loss of model structure and, in turn, to a reduction of prediction accuracy, as demonstrated by Deng et al. [29]. Therefore, a trade-off between accuracy and computational cost is critical, especially when automated reduction techniques are used.

The present paper addresses this issue by introducing a top-down methodology to reduce the complexity of building models, while retaining the model structure, capable of detecting the most suitable model order depending on the specific application requirement. Different levels of model complexity are tested, from BEMs to low order calibrated RC networks, with the aim of detecting a trade off between accuracy and computational costs. Insight is provided on the complexities associated with achieving both conflicting goals (computational tractability vs. energy estimation accuracy) by using a case study representative of mixed-use buildings. A residential building corresponding to a detached house located in Wüstenrot, a district in the Baden-Württemberg region in Germany, was used as case study (Section 3). This building is currently monitored in the framework of a European Commission supported H2020 research project Sim4Blocks [30], which is concerned with the implementation of demand response in building cluster. Experimental data on building energy consumption and internal temperatures were collected and used for validating both the detailed (2.1.1) and simplified white-box models (Section 2.1.2). Then, synthetic data were generated with the purpose of testing the calibration procedure described in Section 2.2. Results and conclusions are described in Sections 4 and 5, respectively.

\section{Materials and Methods}

As outlined in the previous section, the present work is aimed at testing different levels of model complexity for building energy simulation. This section describes the numerical approaches and calibration methods adopted.

\subsection{White-Box Models}

Generally, white-box tools are widely recognised as the most complex models available capable of providing accurate and reliable results. In the present work, the following classification of white-box models is adopted [13]:

- Detailed white-box tools: These models provide a detailed physical representation of the simulated building thanks to the high level of building details required. More accurate results can be 
obtained despite the greater user effort in their implementation and higher computational costs while running. Examples of detailed white-box model are Energy Plus and INSEL (Section 2.1.1).

- Simplified white-box models: These models implement a simplified building physics but they are considered physically-based since all parameters are determined from the actual building properties (e.g., thermal properties of envelope, windows, etc.). No tuning or optimisation procedures are used. BEPS (Section 2.1.2) is an example of simplified white-box model based on the thermo-electric analogy.

\subsubsection{Integrated Simulation Environment Language (INSEL)}

INSEL (Integrated Simulation Environment Language) is a block diagram simulation environment for programming applications from the entire renewable energy sector. Models of system applications can be created with the INSEL graphics editor and, in addition, INSEL offers a unique interface for the extension of the block libraries in programming languages such as Fortran and $\mathrm{C} / \mathrm{C}++$, whereas the blocks used in this work were realised. The aim of the building model is to keep the numerical representation of the building as detailed as possible and let the simplification to be taken at the data model level. Therefore, the same physical model is suitable for any Level of Detail (LOD) of the data model. Specifically, the dynamical building model is based on the nodal method. This method is common for building simulations since it has the advantage of being able to simulate multiple zone buildings. This gives a very good rate between results and calculation time. The principal assumptions thereby are:

- Each building zone is a homogeneous volume characterised by uniform state variables.

- A node represents a room, a wall, a window or else the exterior of the building.

- The thermal transfer equations are solved for each node of the system. This means that the nodal method can be considered as a one-dimensional approach.

The building model is divided into different parts, representing the different components, which can be connected to represent any building. The connection between those parts is made by variables that are considered as internal connectors (i.e., inputs and outputs for the blocks). The model contains a one-dimensional numerical solution of the heat conduction equation for each wall. Additional nodes contain room air and windows. Long wave radiative exchange between the room surfaces is also considered. Model inputs are external boundary conditions such as temperature and irradiance, which is converted to the different orientations. The heat pump model simulates the compressor behaviour based on a polynomial function (according to norm DIN EN 12900). Both heat exchangers on the evaporator and condenser side are taken into account with the NTU method (Number of Transferred Units). This has the benefit, that the calculation process can be simplified because no calculations due to complicated streamlined shapes are needed. In the thermal buffer storage model, all layers are modelled physically. Heat exchange in between the layers is taken into account. The heat is always fed into the appropriate layer. The thermal losses are credited to the specific building zone. Figure 1 gives an overview of the integrated model structure. 


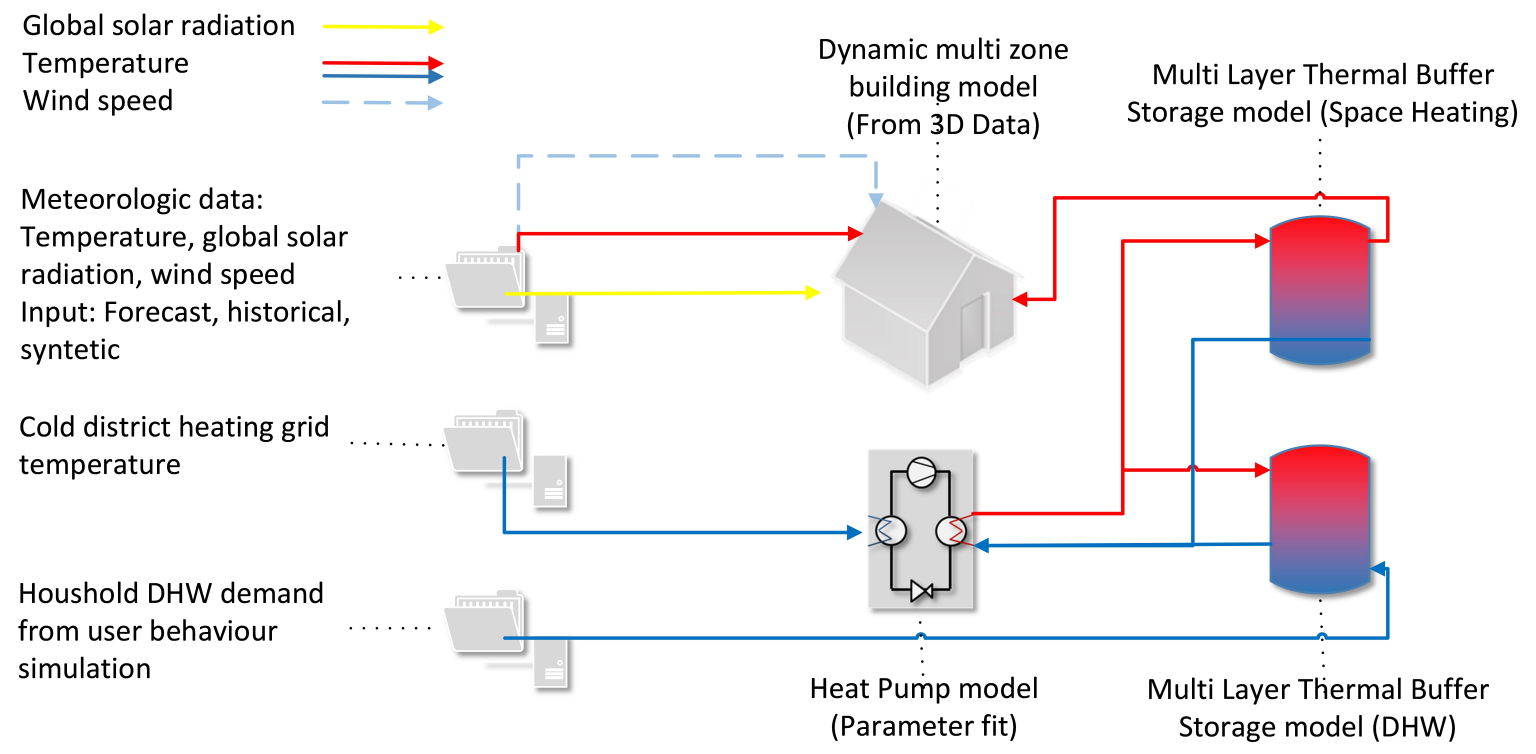

Figure 1. Integrated white-box model (INSEL) combining the dynamic building model with the energy conversion systems.

\subsubsection{Building Energy Performance Simulator (BEPS)}

A simplified numerical model was developed to simulate the Wüstenrot site. The model was developed starting from the work shown in $[19,31]$ and based on the BEPS platform. Implemented in Matlab/Simulink (Figure 2), BEPS model consists of three different blocks representing the different floors of the Wüstenrot building. For each block, a set of ordinary differential equations is implemented to describe the heat transfer occurring between the building and the external air. Each heating/cooling zone $j$ is modelled as a single isotherm volume at temperature $T_{i n t, j}$, and with thermal capacitance $C_{i n t, j}$ which exchanges heat with the surrounding components. The energy balance equation of a single internal heated/cooled zone can be written as in Equation (2) and it takes into account the contributions of: (i) internal heat sources $\left(q_{i s, j}\right)$; (ii) ventilation $\left(\dot{q}_{v, j}\right)$; and (iii) heat gains/losses through the external walls $\left(\dot{q}_{w, j}\right.$ and windows $\left(\dot{q}_{v, j}\right)$.

$$
C_{i n t, j} \frac{d T_{i n t, j}}{d \tau}=\dot{q}_{i s, j}+\dot{q}_{v, j}+\dot{q}_{w, j}+\dot{q}_{w i n, j}
$$

The external walls of each internal zone are lumped together depending on their orientations $x$ (e.g., north, south, east, and west) to allow an accurate computation of the incident solar radiation. The mathematical model for the solar radiation described in De Rosa et al. [19] was adopted. The wall is divided into the internal and external layers, determined depending on the wall thermal characteristics, while the wall thermal capacitance $\left(C_{w, j}^{x}\right)$ is lumped in between them. Regarding the perimeter walls, the energy balances are written as shown in Equation (3), where $\dot{q}_{w-i, j}^{x}$ is the heat flow rate between the internal zone $T_{i n t, j}$ and the wall with orientation $x$, while $\dot{q}_{w-e, j}^{x}$ is the heat flow rate between the in the wall with orientation $x$ and the external environment (represented by the temperature $T_{e}$ for perimeter walls and by the basement temperature $T_{b} g$ for the floor wall). The contribution of the floor heating is represented as a thermal power input $\dot{q}_{h s, j}$, calculated from the heat pump performance curves and lumped to the floor node of each internal zone $j$.

$$
C_{w, j}^{x} \frac{d T_{w, j}^{x}}{d \tau}=\dot{q}_{w-i, j}^{x}+\dot{q}_{w-e, j}^{x}
$$

This model is considered to be a physically-based (i.e., white box) since all parameters (thermal resistances and capacitances, thermal properties, exchange rates, etc.) are determined starting from the actual physical characteristics and/or experimental measurements. No tuning or optimisation 
algorithms are implemented in the model. Notwithstanding, BEPS is also considered to be a simplified model due to the reduction of equations and parameters required to characterise the building physic. This results in lower computational costs, despite a reduction of the model accuracy.

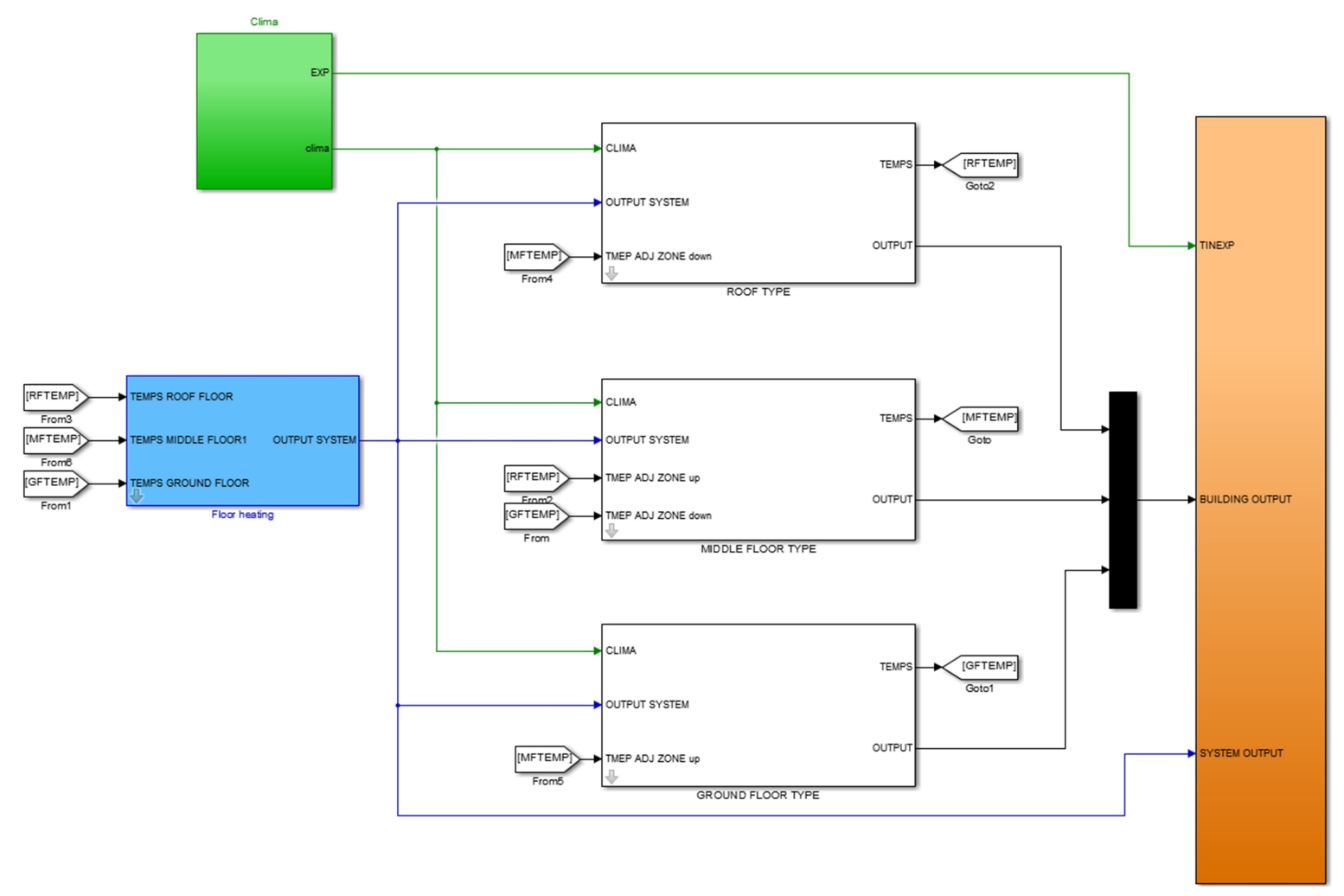

Figure 2. Building Energy Performance Simulator (BEPS) model developed for the Wüstenrot site using Simulink.

\subsection{Reduced Order Model Calibration}

An RC reduction technique was developed based on the Ensemble Calibration (EC) [27], an automated calibration methodology which enables researchers to obtain lumped parameter building models for a number of desired retrofit configurations of a residential dwelling modelled in BEMS environments. Starting from the work presented in Andrade-Cabrera et al. [32], a modelling tool capable of calibrating a simplified lumped parameter model was developed and tested for the Wüstenrot building using the building thermal energy demand as accuracy metric.

Generally, a lumped parameter model can be calibrated with optimal calibration parameters $p_{0}^{*}=\left[R_{0}^{*}, C_{0}^{*}\right]$, while the model thermal response is provided by the room temperature $T_{r, 0}$. Calibration methods correlate the variation in parameters $\left(\Delta_{p}\right)$ which compensates for the variation in thermal performance. This $\Delta_{p}$ can be inferred from the semi-physical modelling. For instance, if external wall insulation is progressively added to the building envelope, a parameter modelling external wall resistance would be expected to increase as the insulation layer thickness increases [27]. During the development of this framework, the key modelling concern consisted of obtaining an accurate lumped parameter building model such that the thermal variations are well captured. To this aim, more accurate white-box models, such as the ones described in Section 2.1, are required. Once these models are validated against metered data obtained from the Wüstenrot pilot site (Section 3), synthetic data can be generated for the calibration process. Then, a lumped parameter building model representative of the target building is designed (i.e., starting from the simplified physical model described in Section 3) and calibrated using the particle swarm optimisation method [33], until an accuracy target is reached. The Root Mean Square Error (RMSE) was adopted as metric to assess the model predictive performance. Generally, the RMSE can be based on the error between the synthetic room temperature time series 
(denoted $T_{E P, k}$ ) and the estimated room temperature obtained using a lumped parameter building energy model $\left(T_{R C, k}\right)$, over a horizon length $N H$, as shown in Equation (4). RMSE values below 0.5 are indicated in the literature as acceptable calibration tolerance [34].

$$
R M S E=\frac{1}{N H} \sqrt{\sum_{k=1}^{N H}\left(T_{E P, k}-T_{R C, k}\right)^{2}}
$$

Although the internal temperature can be used for calibrating building model, the small magnitude of its variations typical of building application may lead to small differences in the calibration metrics and, consequently, it does not provide enough confidence for trimming decision making [32]. Another alternative is to adopt the energy performance as metric for the trimming decision making. This choice comes from the consideration that energy estimation accuracy is the paramount decision key for energy system modellers in most building applications (e.g., for primary energy savings and cost assessment, optimisation algorithms, demand response evaluation, etc.). In the present paper, the estimated building energy consumption $E_{b, e s t}$ is evaluated as follows:

$$
E_{b, e s t}=\sum_{k=1}^{N H} \dot{Q}_{\dot{h e a t}, k} \Delta \tau
$$

where $N H$ is the horizon length and $\Delta \tau$ is the sampling period (i.e., $15 \mathrm{~min}$ ). The estimated energy consumption $E_{b, e s t}$ allows the comparison of the accuracy between the full model $\left(E_{b, f m}^{z}\right)$ with the reduced sub-models $z\left(E_{b, r m}^{z}\right)$ created by the trimming procedure described hereafter. The comparison is carried out by computing the energy estimation error defined as the percentage deviation of the energy consumption predicted by the reduced model with the one estimated by the full model, as shown below:

$$
E E E=\frac{\left|E_{b, r m}^{z}-E_{b, f m}^{z}\right|}{E_{b, f m}^{z}}
$$

A linear optimisation problem aimed at minimising the target function $J\left(\dot{Q}_{\text {heat }}\right)$ is used to estimate the building energy model. The heat input $\dot{Q}_{\text {heat }}$ can be related to the room temperature $T_{R C, k}$ by considering the building dynamics shown in Equation (7), where the building model state is described by the matrices $F, G$ and $H$. The array $x_{k}$ is composed by all the node temperature (i.e, rooms and walls temperature) and represents the building model state, while $d_{k}$ is the exogenous disturbance array (i.e., weather variables such as ambient temperature).

$$
x_{k+1}=F x_{k}+G \dot{Q}_{h e a t, k}+H d_{k}
$$

The constraints on the room temperature $T_{r, k}$ and heat input $\dot{Q}_{\text {heat }}$ implemented are shown in Equations (8) and (9), where $S P_{l o w, k}$ and $S P_{h i g h, k}$ are the minimum and maximum values of the room temperature allowed to meet the comfort criterion. Similarly, $\dot{Q}_{\text {heat,min }}$ and $\dot{Q}_{\text {heat,max }}$ represent the lower and upper values of the heat input allowed, which depend on the energy system considered.

$$
\begin{gathered}
S P_{\text {low }, k} \leq T_{r, k} \leq S P_{\text {high }, k} \\
\dot{Q}_{\text {heat }, \text { min }} \leq \dot{Q}_{\text {heat }} \leq \dot{Q}_{\text {heat }, \text { max }}
\end{gathered}
$$

Starting from the full RC model (order $N$ ), which was calibrated against synthetic data obtained from the E+ model shown in Section 2.1, the trimming procedure reduces progressively the model order by removing one thermal capacitance adjacent to the room node $\left(T_{r}\right)$ per iteration. Therefore, the order of the new models will be $N-1$ after the first iteration, $N-2$ after the second iteration, etc. Only one node is removed at a given time, with the exception of the attic node, which requires the removal of both the attic and roof nodes. Each sub-model resulting from the node removal is 
re-calibrated using the RMSE as a metric and the error in estimating the energy consumption $(E E E)$ is then evaluated. Next, the node trimming corresponding to the smallest energy estimation error with respect to the full model is selected and omitted to create a new trimmed sub-model with order $N-1$. The procedure is then repeated for further iterations until the lowest model order possible (i.e., $1 C$ ) is obtained. The reasoning behind this model trimming strategy is that the sub-model with the highest energy accuracy among its peers is more representative of the full model and, thus, the best topology solution at the level of complexity being evaluated. The whole procedure is summarised in Figure 3.

The present paper describes the results obtained from testing this $\mathrm{RC}$ reduction technique using synthetic data from the Wüstenrot site (see Section 3) in order to determine the trade-off between accuracy and computational cost. More details about the RC models adopted and tested are reported in Section 4.2.
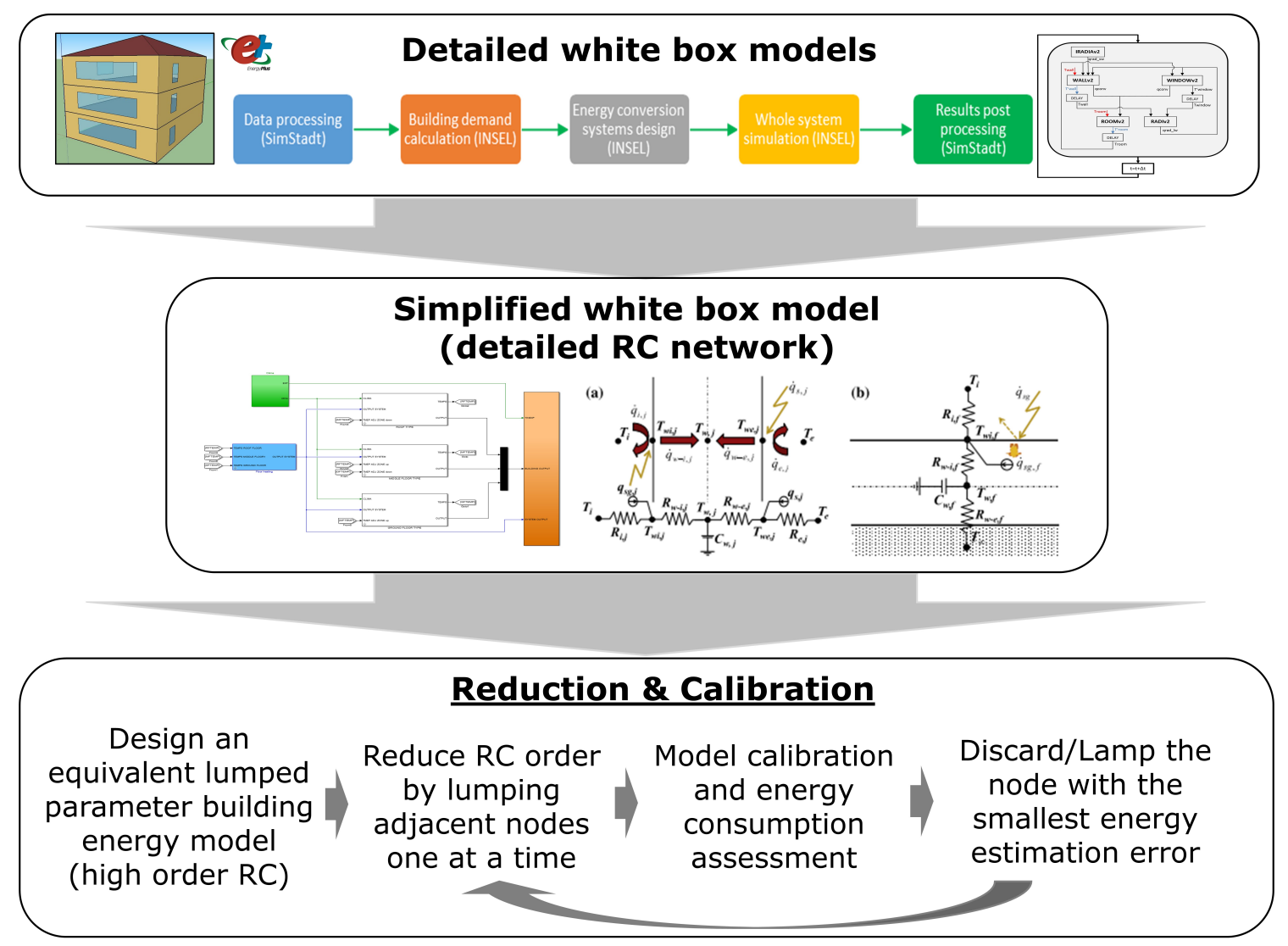

Figure 3. Schematic of the adopted methodology. Detailed white-box models: Energy+ and INSEL. Simplified white-box models: BEPS. Low order models: reduction (trimming) and calibration procedure.

\section{Case Study}

The present work is based on a plus energy district, which serves as pilot demonstration site in the German community of Wüstenrot (Figure 4a). This district consists of 17 newly built, highly energy efficient residential buildings. The concept combines low depth geothermal systems, heat pumps and PV systems of sufficient size of $6-13 \mathrm{kWp}$ for each building. The low temperature energy source of the heat pumps is a central cold-water grid, which consists of a large innovative near surface agro-thermal system (a variation of geothermal collectors). 

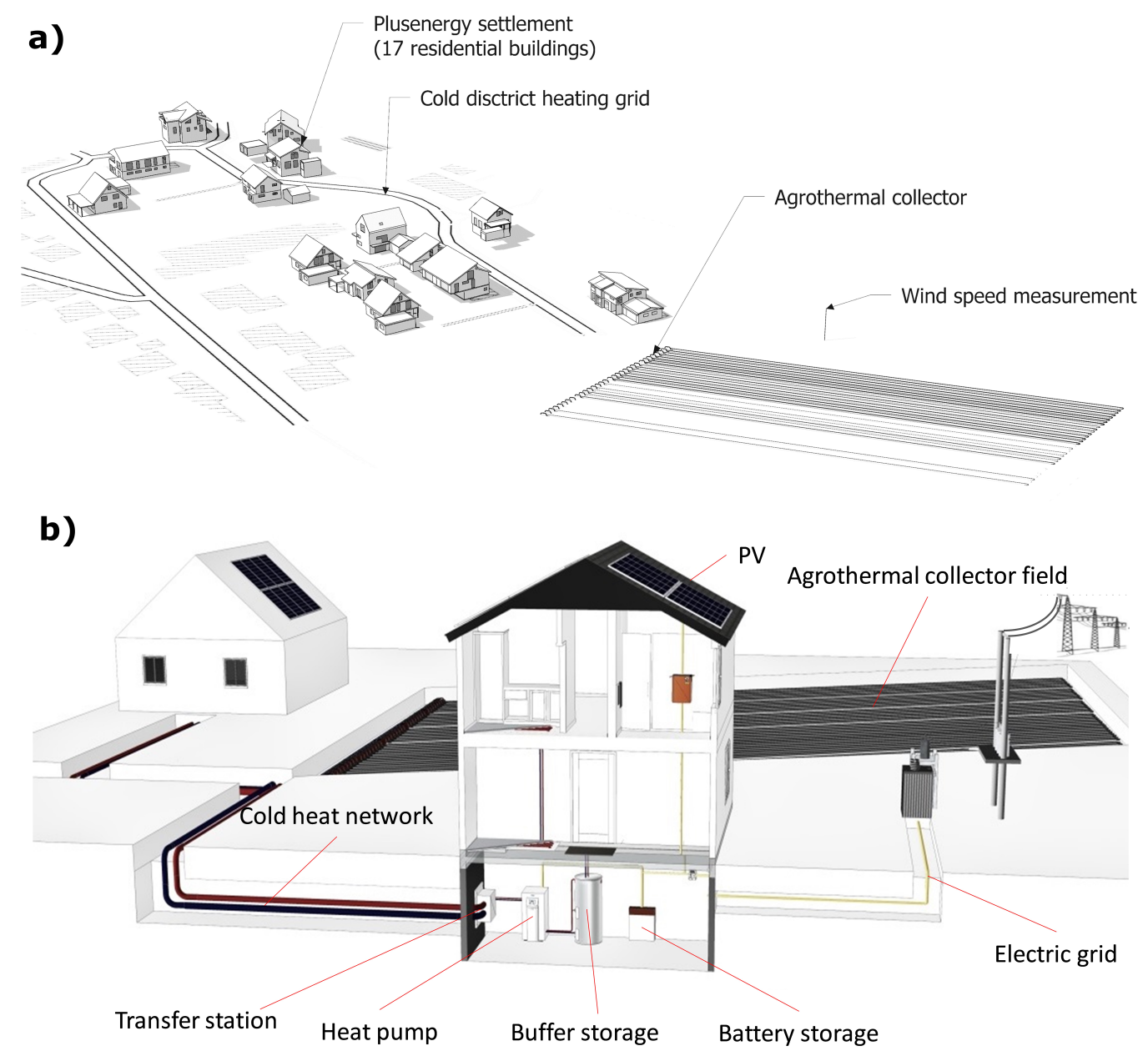

Figure 4. (a) The Wüstenrot pilot site "Vordere Viehweide". (b) Schematic of the building considered.

Since the present research is aimed at assessing different levels of model complexity capable of predicting the short-term energy demand at building level, the developed models were mainly focused on the building envelope characteristics, rather than on the energy system. A detailed description of the thermal characteristics of the building envelope is therefore reported in the following sections.

\section{Experimental Building}

The considered building (Figure $4 \mathrm{~b}$ ) has a living area of $310 \mathrm{~m}^{2}$, a PV system with $13.7 \mathrm{kWp}$, a brine/water heat pump with $22 \mathrm{~kW}$ thermal output, two buffer storage tanks (1000 L space heating, $400 \mathrm{~L} \mathrm{DHW)} \mathrm{and} \mathrm{a} 5 \mathrm{kWh}$ battery storage, which however is used for the optimisation of PV self-consumption only. Detailed monitoring data are available for all relevant thermal and electrical energy flows as well as for the relevant temperatures and weather data (ambient temperature and global radiation). The building is located in a temperate seasonal climate zone, typical of Germany. More building details can be found in Tables 1 and 2 .

All relevant building energy flows are measured and stored in a cloud-based database. In this cloud, the detailed monitoring data as well as the thermal simulation are available in a virtual machine. The thermal demand and temperatures are logged in small intervals, $30 \mathrm{~s}$ for thermal data and as low as $5 \mathrm{~s}$ for electricity data, which can be accessed via locally installed tools (Figure 5). Figure 6 shows the measured buildings energy demand, the heat pumps COP and the heat source temperature on a monthly basis for the year 2017. 
Table 1. Building geometry.

\begin{tabular}{|c|c|c|}
\hline Parameter & \multicolumn{2}{|c|}{ Value/Range } \\
\hline Latitude & \multicolumn{2}{|c|}{$49.6^{\circ}$ North } \\
\hline Longitude & \multicolumn{2}{|l|}{$9.6^{\circ}$ East } \\
\hline Elevation & \multicolumn{2}{|l|}{$495 \mathrm{~m}$} \\
\hline Number of storeys & \multicolumn{2}{|l|}{3} \\
\hline \multirow{8}{*}{ External walls } & North & $109.9 \mathrm{~m}^{2}$ \\
\hline & South & $147.3 \mathrm{~m}^{2}$ \\
\hline & East & $84.5 \mathrm{~m}^{2}$ \\
\hline & West & $85.0 \mathrm{~m}^{2}$ \\
\hline & Basement & $139.9 \mathrm{~m}^{2}$ \\
\hline & Flat roof & $25.0 \mathrm{~m}^{2}$ \\
\hline & Tilted roof (south) & $46.9 \mathrm{~m}^{2}$ \\
\hline & Tilted roof (north) & $78.9 \mathrm{~m}^{2}$ \\
\hline \multirow{4}{*}{ Windows } & North & $36.5 \mathrm{~m}^{2}$ \\
\hline & South & $28.6 \mathrm{~m}^{2}$ \\
\hline & East & $5.2 \mathrm{~m}^{2}$ \\
\hline & West & $13.0 \mathrm{~m}^{2}$ \\
\hline Solar heat gain coefficient & \multicolumn{2}{|l|}{0.583} \\
\hline Roof pitch & \multicolumn{2}{|l|}{$15^{\circ}$} \\
\hline Envelope leakages & \multicolumn{2}{|l|}{$0.31 / \mathrm{h}$} \\
\hline Wall absorptance & \multicolumn{2}{|l|}{0.2 (white) } \\
\hline
\end{tabular}

Table 2. Building construction characteristics.

\begin{tabular}{llll}
\hline Part & $\begin{array}{l}\text { U-Value } \\
\left(\mathbf{W} / \mathbf{m}^{2} \mathbf{k}\right)\end{array}$ & $\begin{array}{l}\text { Thickness } \\
\mathbf{( c m )}\end{array}$ & Construction \\
\hline External walls & 0.21 & 36.5 & $\begin{array}{l}\text { Autoclaved aerated concrete/brickwork } \\
(\lambda=0.08 \mathrm{~W} / \mathrm{mK})\end{array}$ \\
\hline Basement plate & 0.27 & 15 & $\begin{array}{l}\text { Reinforced concrete }(\lambda=0.08 \mathrm{~W} / \mathrm{mK}) \\
\text { Thermal insulation } \mathrm{PU}(\lambda=0.02 \mathrm{~W} / \mathrm{mK})\end{array}$ \\
\hline Flat roof & 0.27 & 20 & $\begin{array}{l}\text { Reinforced concrete }(\lambda=0.08 \mathrm{~W} / \mathrm{mK}) \\
\text { Thermal insulation } \mathrm{PU}(\lambda=0.035 \mathrm{~W} / \mathrm{mK})\end{array}$ \\
\hline Tilted roof & 0.14 & 20 & Thermal insulation mineral wool above rafter $(\lambda=0.03 \mathrm{~W} / \mathrm{mK})$ \\
\hline External floor & 0.23 & 20 & $\begin{array}{l}\text { Reinforced concrete }(\lambda=0.08 \mathrm{~W} / \mathrm{mK}) \\
\text { Thermal insulation PU }(\lambda=0.035 \mathrm{~W} / \mathrm{mK})\end{array}$ \\
\hline $\begin{array}{l}\text { Inner walls } \\
\text { to unheated }\end{array}$ & 0.31 & 24 & $\begin{array}{l}\text { Auto-claved aerated concrete } / \mathrm{brickwork} \\
(\lambda=0.08 \mathrm{~W} / \mathrm{mK})\end{array}$ \\
\hline & & Three layer & $\begin{array}{l}\text { Thermal insulation glazing } \\
\text { Frame percentage: } 0.3\left(U_{f}=1.00\right) \\
\text { Gas filling: Krypton }\left(U_{g}=0.52\right) \\
\text { Transmissivity: } 0.583\end{array}$ \\
\hline
\end{tabular}




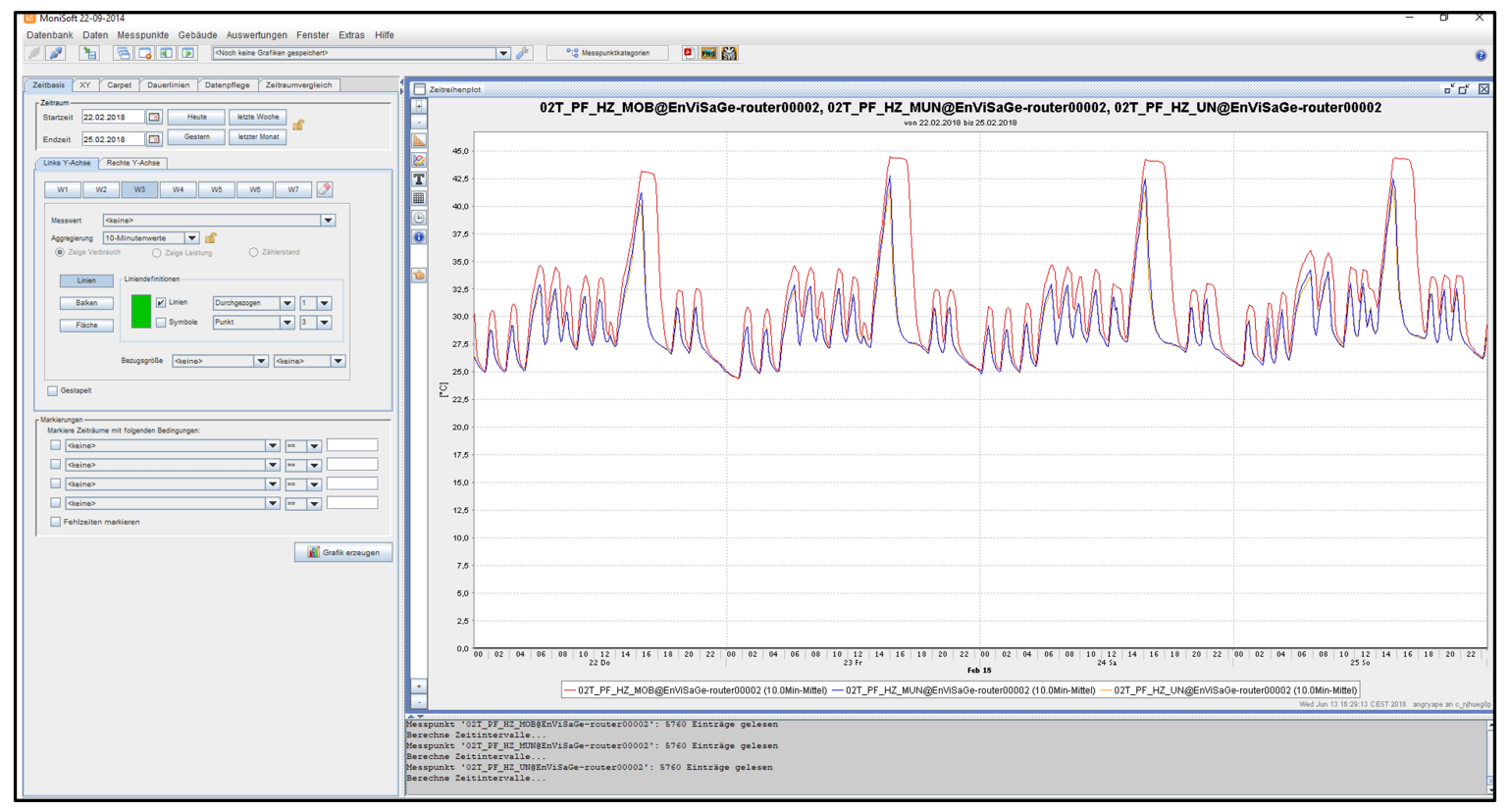

Figure 5. Real time monitoring of the Wüstenrot pilot site.

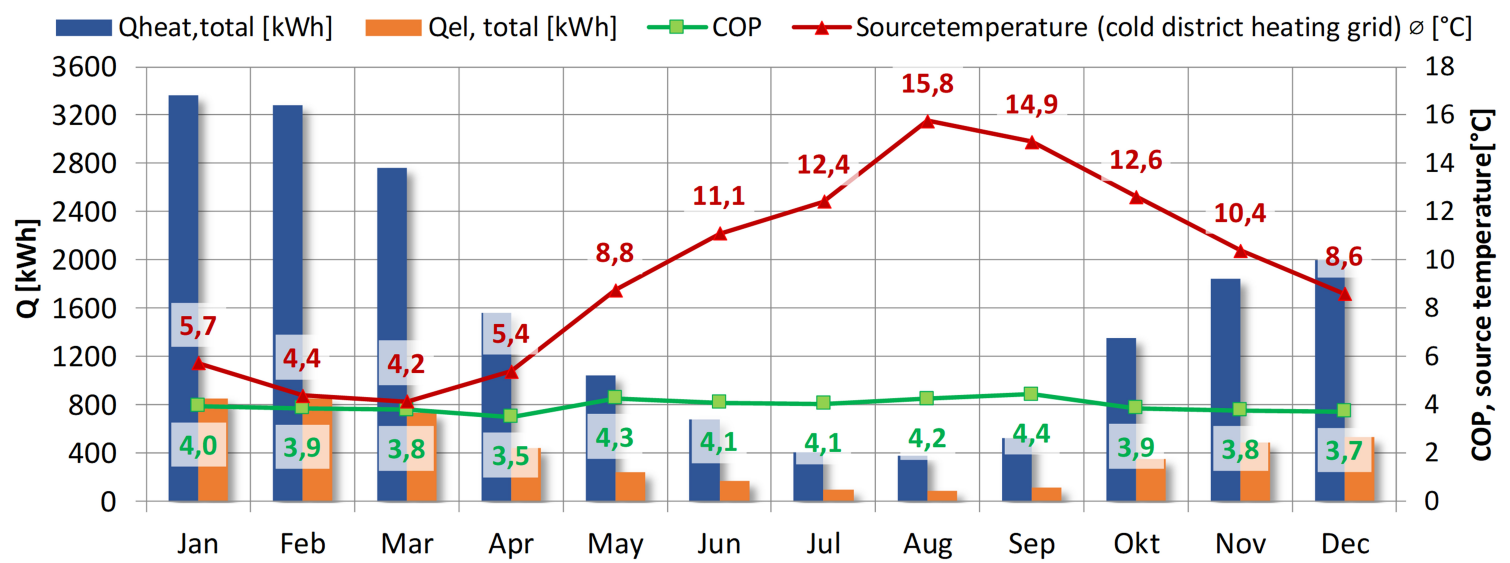

Figure 6. Measured heating demand and heat pump COP on monthly basis (year: 2017).

\section{Results and Discussion}

\subsection{Detailed Model Analysis}

The white-box model described in Section 2.1 was validated against experimental data collected during a 33-day period between February and March 2018. Figure 7 reports the metered climatic data (ambient temperature and solar radiation) during the considered period. The validation was carried out comparing the internal temperature and the building cumulative thermal consumption profiles predicted by the white-box models with the experimental data collected from the pilot site. The numerical results from a detailed Energy Plus model was also used as reference. 
a)

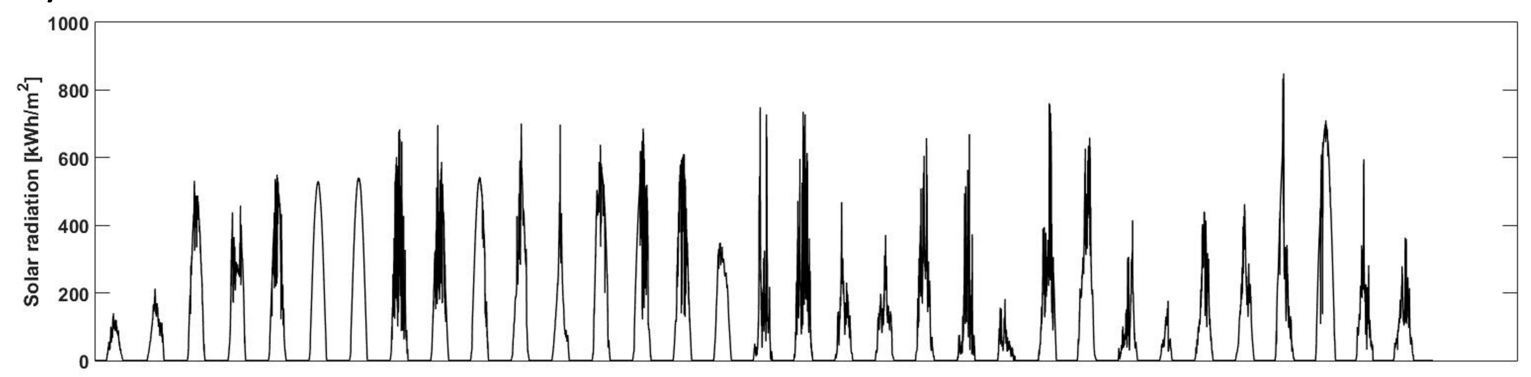

b)

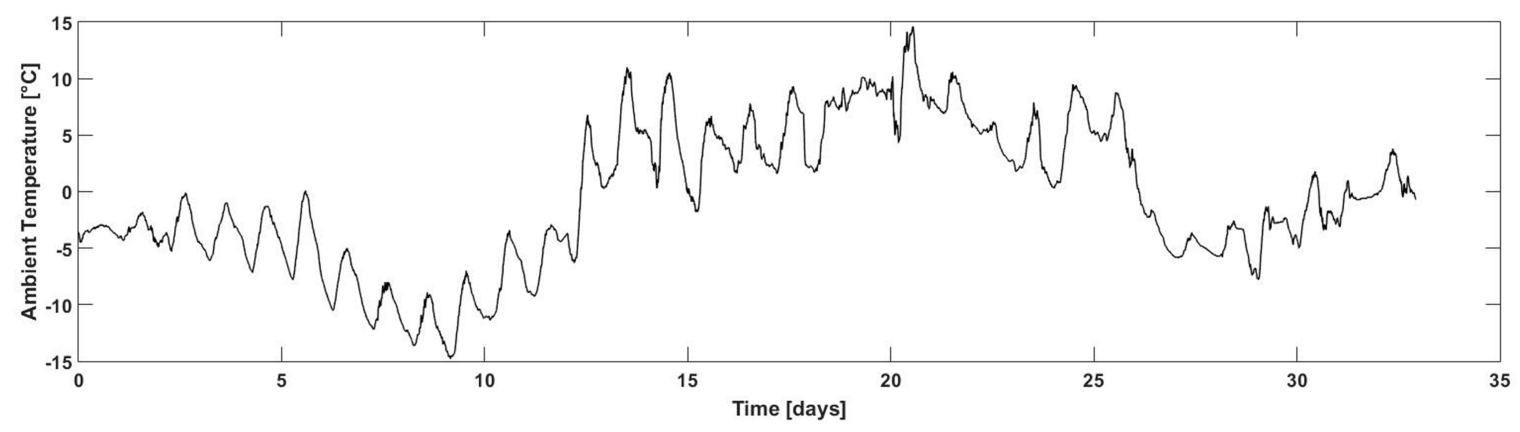

Figure 7. (a) Ambient temperature; and (b) solar radiation measured at the Wüstenrot pilot site during the period considered

Figure 8a reports the internal temperature profiles during the simulated period for the three models considered (Energy Plus, INSEL and BEPS). It can be observed from the graph resolution that the fluctuations experienced by the internal temperature profiles are contained in the dead-band set by the control system $22{ }^{\circ} \mathrm{C} \pm 1{ }^{\circ} \mathrm{C}$ for both the experimental and numerical results. Figure $8 \mathrm{~b}$ reports the comparison between the cumulative building thermal energy demand measured from the pilot site and the one obtained from the different numerical models. A good match between the experimental and numerical results can be observed for all the models developed. In particular, Energy Plus provided the best accuracy with an average estimation error lower than $4 \%$, while INSEL and BEPS showed slightly less accuracy, with average values below $7 \%$ and $9 \%$, respectively.

Figure 9 illustrates the comparison between the measured and predicted building energy consumptions at daily basis over the considered period. It can be noted that both Energy Plus and INSEL showed a good agreement with the experimental results, with RMSE of 0.08 and 0.11, respectively. On the other hand, BEPS showed a worse performance, with a RMSE of 0.15. In fact, even if BEPS can be considered a white-box model, since its parameters have a physical meaning, the simplified approach was used to determine the thermal network and the correspondent thermal resistances and capacitances. Even though the model is accurate in a long-term perspective (weekly, monthly and yearly calculations [19]), the simplified approach makes the model less accurate at lower time resolution (i.e., daily and below). This is an important aspect when short-term assessment, like the one required for activating demand response actions, and optimisation algorithms are implemented. 
a)

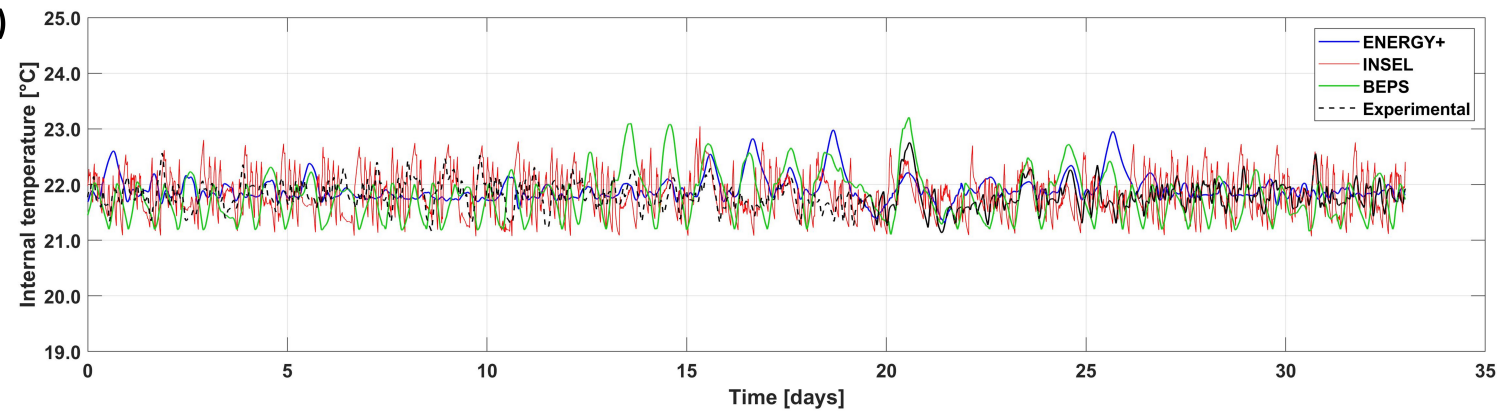

b)

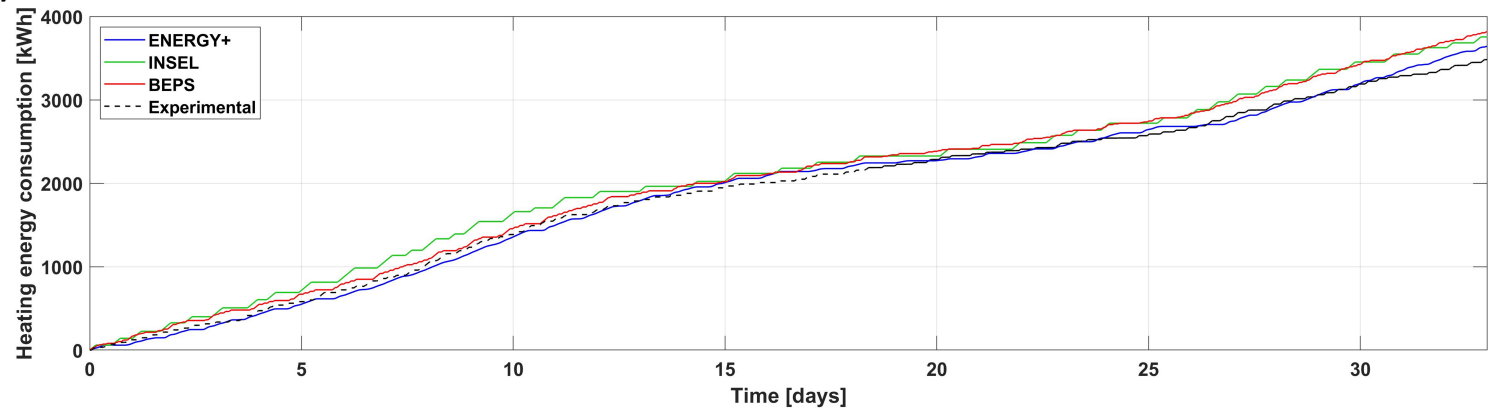

Figure 8. (a) Comparison between internal temperature profiles from E+, INSEL and BEPS and experimental data. (b) Cumulative building heat demand in the period considered.

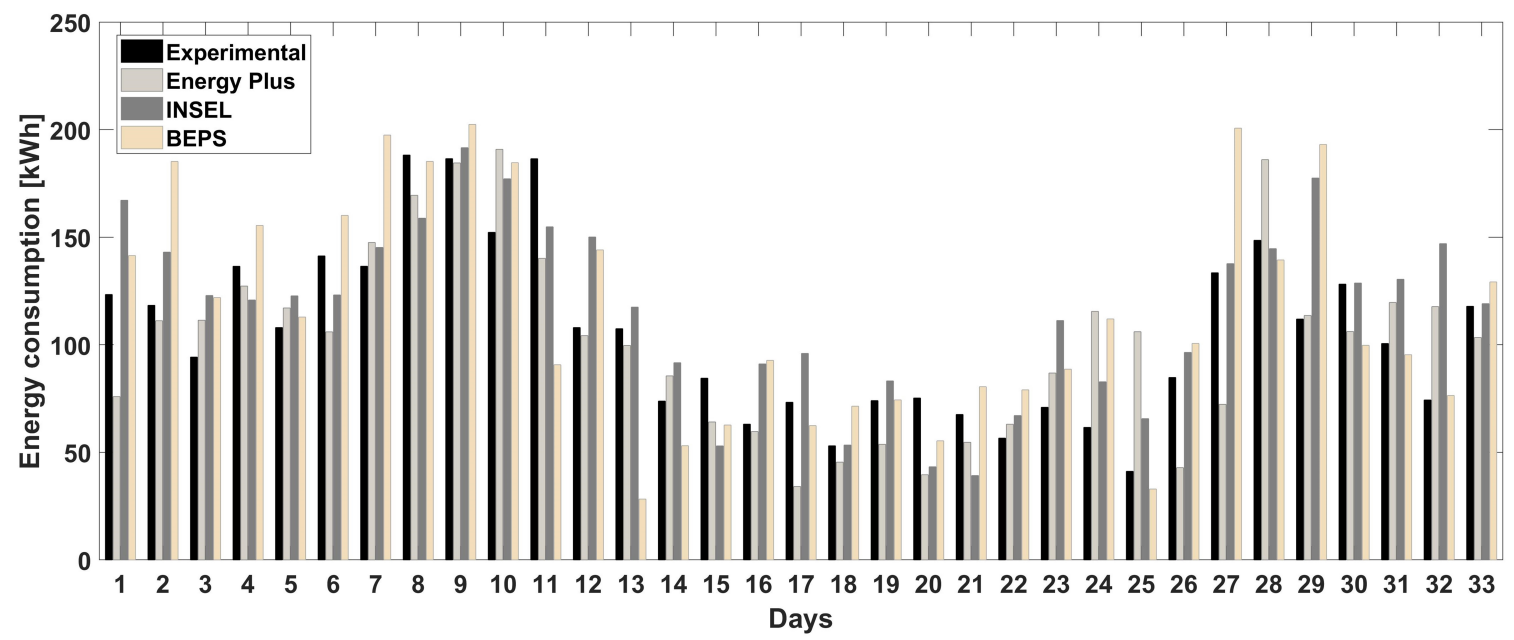

Figure 9. Comparison between experimental and numerical (E+, INSEL and BEPS) daily building heat demand profiles in the considered period.

\subsection{Results of the Calibration Procedure}

The $\mathrm{RC}$ reduction technique described in Section 2.2 was tested using synthetic data from the Wüstenrot site starting from an heterogeneous lumped parameter building model used as high order model for the calibration procedure (Figure 10). The multi-zone building is approximated as a two-zone dwelling using the average room temperature $\left(T_{r}\right)$ of the three heated zones, while $T_{a m b}$ is the external dry-bulb outdoor temperature. Nodes $C_{w 1}$ and $C_{w 2}$ represent the outer and inner leaves of the external walls, while $C_{a}$ is the thermal capacitance of the room air mass at temperature $T_{r}$. Node $C_{i n t}$ captures the thermal mass of the internal partitions and other slower dynamics inside the building. The heat gains due to solar radiation on the external walls, $Q_{s, \text { wall }}$, are applied directly to node $C_{w 1}$. The window solar heat gain $Q_{s, \text { win }}$ and the heating power input $Q_{\text {heat }}$ are split between $C_{a}$ and $C_{\text {int }}$ via the splitting fractions $f_{1}$ and $f_{2}$. Node $C_{\text {ceil }}$ models the ceiling between the room node $C_{r}$ and the attic node $C_{a t t i c}$. The heat gains due to incident solar radiation on the roof surfaces, $Q_{s, \text { roof }}$, are applied to the roof node 
$C_{\text {roof }}$. Finally, a ground node $C_{g n d}$ is added to model the heat transfer between the heated volume and the building foundations.

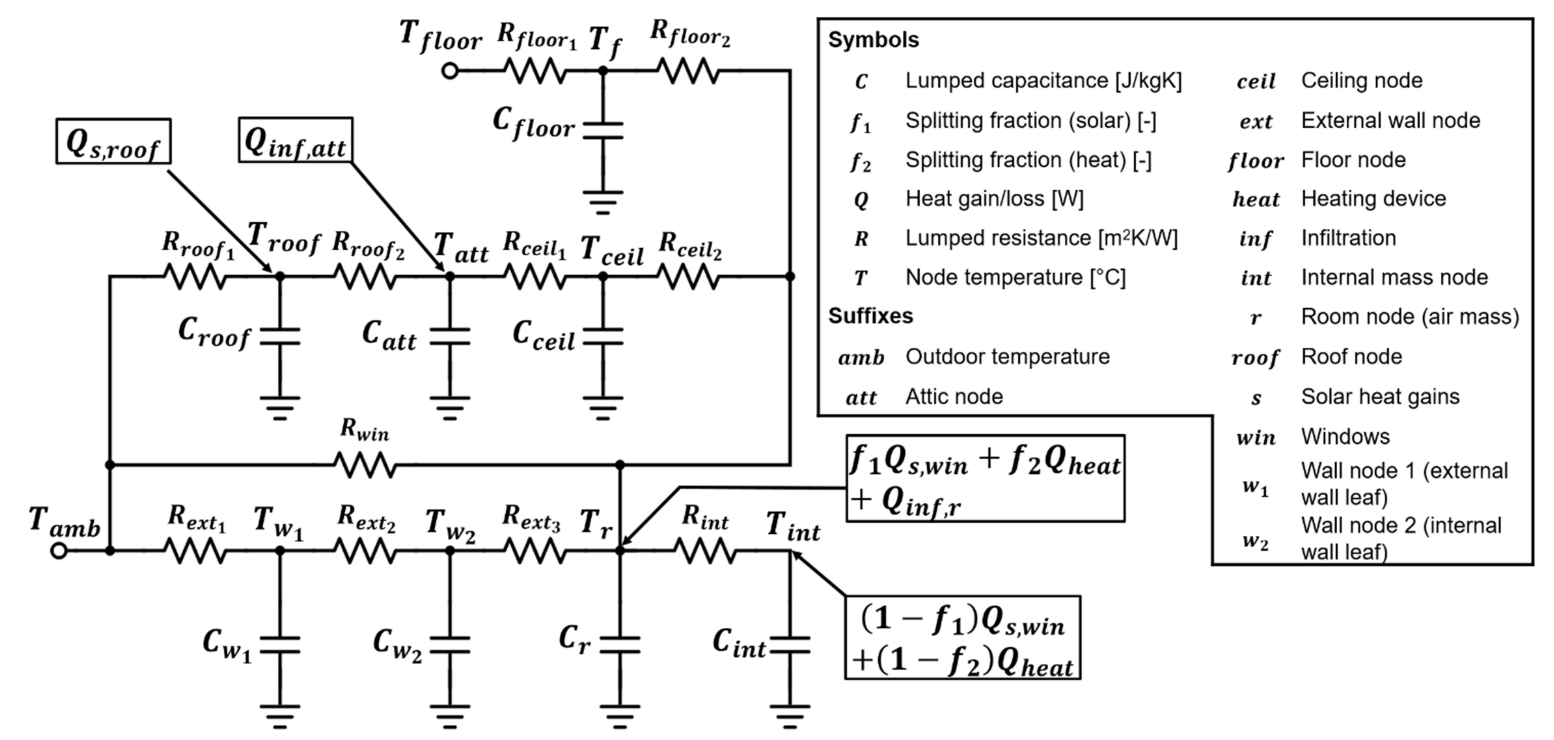

Figure 10. Heterogeneous lumped capacitance models proposed for the calibration technique [32].

The lumped parameter model described above was then calibrated with the procedure described in Section 2.2, by using synthetic data covering all the heating season obtained from the validated model implemented in Energy Plus (Section 4.1). The BEM model in Energy Plus was developed and used to determine the annual heating energy consumption, resulted to be equal $12.29 \mathrm{MWh}$ /year. This result is inline with the metered data and the simulation performed with the calibrated white-box model presented in Section 4.1. The results obtained from the calibration are reported in Table 3, while Figure 11 shows the comparison between the internal temperature trajectory from the calibrated model and Energy Plus during a typical day with a time step of $10 \mathrm{~min}$. It can be noted that, despite the overall performance, the calibrated high order lumped model tended to overestimate the internal temperature. This resulted in an annual energy overestimation of $7.16 \%$ with respect to the selected BEM model. The key reason behind the discrepancy consists of the nature of the operations of the building models. The lumped parameter building energy models, obtained in Andrade-Cabrera et al. [35], were conceived for their linear co-optimisation with energy systems (e.g., power grid models). Thus, low-level controllers were not developed, as the linear optimisation algorithm would identify the optimal heating load based on the optimisation objective (e.g., cost minimisation) and constraints (e.g., reaching the set-point during comfort hours). This approach enables the co-optimisation of the building and grid models, allowing for the full exploitation of thermal mass flexibility and power systems flexibility. The linear optimisation problem must reach the set-point when required, otherwise the linear optimisation problem is unfeasible.

Table 3 shows the performance metrics of each sub-model detected during the optimisation procedure. The nodes considered in the first iteration are: (i) the second external wall node $C_{w 2}$; (ii) the floor node $C_{\text {floor }}$; and (iii) the internal mass node $C_{i n t}$. At this stage, the removal of the ceiling node $C_{c e i l}$ was not possible since it would have resulted in a mixture of the conditioned and unconditioned spaces. Instead, the attic node $C_{\text {att }}$ and the roof node $C_{\text {roof }}$ were considered. It was assumed that the attic temperature $T_{\text {att }}$ could be deemed to be similar to the outdoor temperature (which is likely to be the case for winter conditions). 
Table 3. Performance metrics and computational time of the different models developed by the reduction methodology.

\begin{tabular}{llcccc}
\hline Building Models & & $\begin{array}{c}\text { RMSE } \\
(\mathbf{K})\end{array}$ & $\begin{array}{c}\text { Energy } \\
\text { (MWh/y) }\end{array}$ & $\begin{array}{c}\text { Estimation Error } \\
\mathbf{( \% )}\end{array}$ & $\begin{array}{c}\text { Computational Time } \\
\text { (s) }\end{array}$ \\
\hline High order model & & 0.36 & 13.17 & 7.16 & 61.56 \\
\hline \multirow{4}{*}{ First iteration } & Wall & 0.37 & 13.54 & 10.17 & 45.85 \\
& Floor & 0.36 & 13.29 & 8.14 & 44.65 \\
& Attic & 0.36 & 13.45 & 9.44 & 29.67 \\
& Internal mass & 0.71 & 14.56 & 18.47 & 45.61 \\
\hline \multirow{3}{*}{ Second iteration } & Wall & 0.37 & 16.22 & 31.98 & 20.79 \\
& Attic & 0.37 & 13.43 & 9.28 & 24.53 \\
& Internal mass & 0.58 & 16.23 & 32.06 & 31.98 \\
\hline \multirow{3}{*}{ Third iteration } & Wall & 0.38 & 19.03 & 54.84 & 24.09 \\
& Internal mass & 0.77 & 16.31 & 32.71 & 23.95 \\
& Ceiling & 0.37 & 13.28 & 8.06 & 21.77 \\
\hline \multirow{2}{*}{ Fourth iteration } & Wall & 0.60 & 14.08 & 14.56 & 4.97 \\
& Internal mass & 1.03 & 13.78 & 12.12 & 3.82 \\
\hline \multirow{2}{*}{ Standard models } & 3R2C & 1.38 & 13.87 & 12.86 & 1.35 \\
& 1R1C & 1.24 & 14.18 & 15.38 & 0.92 \\
\hline
\end{tabular}

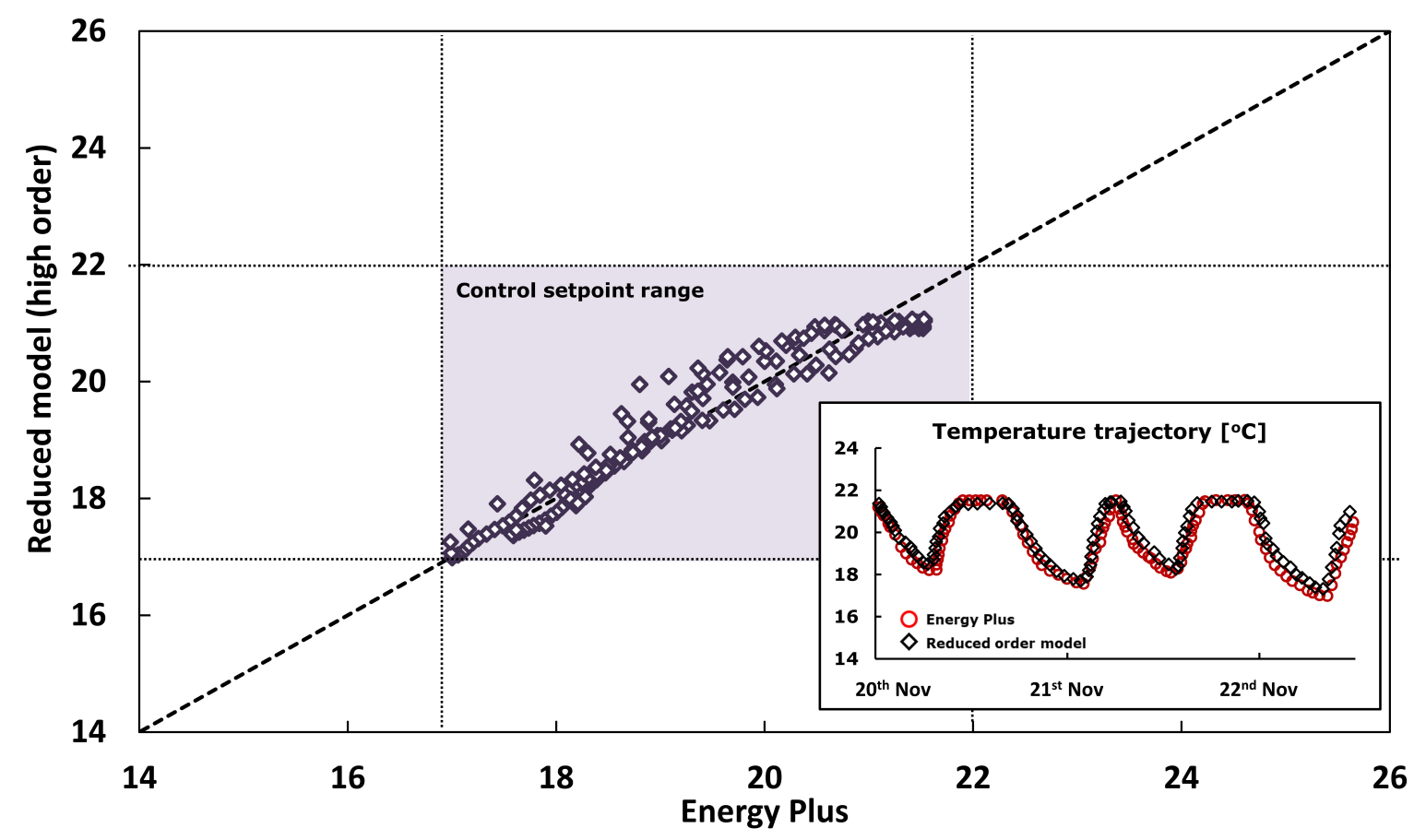

Figure 11. Temperature trajectories computed by Energy Plus and the high order reduced model during three consecutive days in November.

The results of the first iteration showed that the inner wall node $C_{\text {floor }}$ was the one with the lowest energy estimation error $(8.14 \%)$ and, therefore, it was triggered according to the procedure described in Section 4.2. It is interesting to note that the sub-models with the floor and attic nodes removed showed energy estimation errors higher that the high order model, even if similar RMSE accuracy metric were obtained. Hence, the reticence of using this calibration metric as trimming decision variable. Finally, the computational speed decrement is already significant at this stage of the trimming procedure, since computational times reduced between $25 \%$ and $45 \%$ with respect to the full model. 
Starting from the results obtained from the first iteration, a subsequent trimming procedure was carried out. The results are shown in Table 3 , where it is possible to note that the attic node $C_{\text {att }}$ showed the smallest energy accuracy forecast error (i.e., $9.28 \%$ ) and, consequently, was chosen for a further model reduction. This selection implied that both the $C_{\text {roof }}$ and $C_{a t t}$ were removed at the same time. Despite this double removal, the computational time of this trimmed model (i.e., $24.53 \mathrm{~s}$ ) exceeded the one obtained for the sub-model in which the wall node $\left(C_{\text {wall }}\right)$ was removed.

The third iteration was then performed starting from the sub-model resulting from the trimming of the internal wall node $C_{w 2}$ (first iteration) and of the attic node $C_{a t t}$ (second iteration). Observing the results in Table 3, it can be noted that, from a model calibration point of view, the internal mass node represented the largest error. This is due to the fact that the removal of the heating input splitting fractions $f_{1}$ and $f_{2}$ significantly altered the performance of the model. On the other hand, the sub-model corresponding to the ceiling node $C_{\text {ceil }}$ removal gave the lowest energy estimation error (i.e., $8.06 \%$ ) and, therefore, it was chosen for the further model reduction. It can also be noted that this stage of the reduction procedure may represent a potential trade-off point for the selected target building since all sub-models showed negligible improvements with respect to the previous step.

After all the above mentioned nodes were discarded, the fourth iteration was performed to reach an even reduced sub-model. it can be observed in Table 3 that the sub-model resulting form triggering the external wall node $C_{w 1}$ had the lowest energy estimation error. Therefore, for the purposes of the current case study, a low-complexity model of a third order, featuring external wall nodes $C_{w 1}$ and $C_{w 2}$, as well as the room node $C_{r}$ and internal mass $C_{i n t}$, resulted in an energy error estimation of $12 \%$, while being $93 \%$ faster with respect to the full model. It is important to highlight that even if the model can be deemed inaccurate for some applications (e.g., investment model), it would be possible that modellers devising systems at scale might consider these trade-offs as suitable for their needs.

Finally, Table 3 reports the results obtained from low order models (i.e., 3R2C and 1R1C) as reference. It can be noted that the 1R1C model shows an RMSE value lower than the 3R2C model, while the 3R2C model has a lower energy estimation error. Hence, the importance of using energy metrics in lieu of calibration metrics for model reduction purposes. The 1R1C results in a topology with a potentially acceptable underestimation of $-15.38 \%$ on an annual basis, while using only $1.4 \%$ of the computational time $(0.92 \mathrm{~s})$ of the full model $(63.12 \mathrm{~s})$. However, as explained below, this result may not translate to other scenarios.

Figure 12 summarises the results by showing the trade between the model accuracy (Figure 12a) and the model complexity (i.e., computational cost in Figure 12b). The number $n$ of nodes of the $\mathrm{RC}$ thermal network (i.e., the thermal capacitances and denoted as $n C$ in Figure 12), represents the number of ordinary differential equations to be solved by the numerical model and, therefore, it is a direct measure of the details in simulating the building. For the sake of simplicity, only selected models prior to trimming are represented in Figure 12). It can be noted that, for this particular building configuration, a potential trade-off between computational complexity and energy prediction accuracy corresponds to a model topology with four nodes $(4 C)$ or three nodes $(3 C)$.

It is important to note that the model reduction procedure presented in this work keeps the frequency characteristics of the original model with respect to most of the inputs. However, some responses are lost during the order reduction procedure due to the trimming. An example is the frequency response of the system with respect to the roof solar radiation $Q_{s, \text { roof }}$ which cannot be considered satisfactory, since the balanced truncation algorithm is unable to capture the impact from the roof solar radiation when considered as an input.

Finally, several limitations can be spotted from this reduction automatic procedure. Firstly, the balanced truncation methodology may result in conservative models that restrict researchers from potential better trade-offs on model complexity and accuracy. Moreover, a loss of physical meaning in the resulting state-space model occurs as the result of the calibration procedure, which transforms the sub-models into grey-box models. This means that any alteration in the building characteristics (i.e., by retrofitting the building fabric) could rapidly be associated with building 
physical characteristics and the corresponding parameter change in the reduced RC model. On the other hand, such relationships are not straightforward (or have not been proven yet) when automated model reduction methodologies are applied.
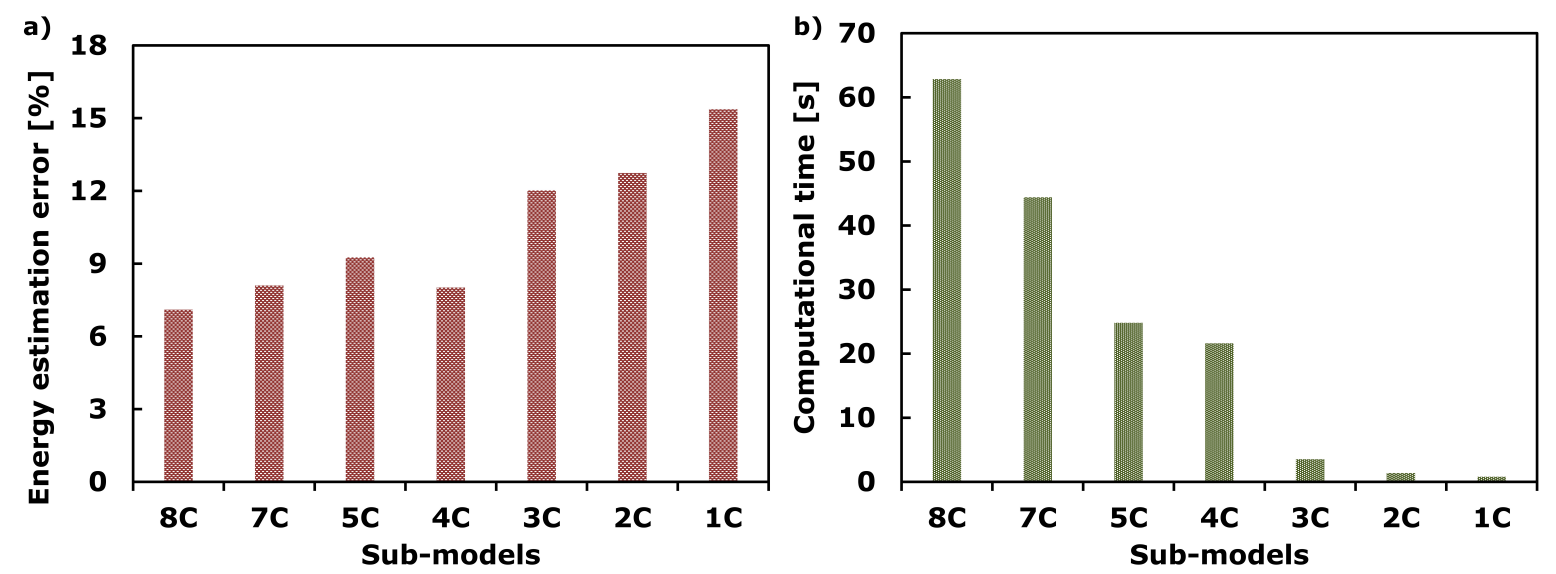

Figure 12. Trade-off between (a) model accuracy and (b) computational efforts.

\section{Conclusions}

The present paper introduces an iterative methodology to reduce the complexity of building models in order to detect a trade off between accuracy and computational costs depending on the specific model applications. Different levels of model complexity were tested, from white-box BEMs and RC models to low-order calibrated RC models. Experimental data from a residential building located in Wüstenrot (Germany) were collected and used to validate two detailed white-box models (INSEL and Energy Plus) and a simplified white-box model (BEPS). The validation process, performed in terms of building thermal demand, showed good agreements between experimental and numerical results, with RMSE of $0.08,0.11$ and 0.15 of Energy Plus, INSEL and BEPS, respectively.

Starting from the validated models, synthetic profiles were generated from the validated detailed white-box models (i.e., Energy Plus) to be used for the reduction procedure. The proposed methodology has the advantage of keeping the physical structure of the original lumped parameter model, thus enabling the use of the trimmed lumped parameter building model for other applications. A trade off between accuracy and computational costs can therefore be found depending on the particular application intended for the model. Considering the specific case study analysed in the present work, a trade-off demarcation between computational complexity and energy prediction accuracy was observed for a model topology with four nodes $(4 \mathrm{C})$ or three nodes (3C).

In contrast with automated model reduction methods, where the compromise between building and system energy modellers can be evaluated ex post only, the user-driven approach adopted allows insights at each intermediate iteration to be obtained. This allows the procedure to be adapted to the specific application considered. On the other hand, this iterative and heuristic model reduction approach might be outperformed by alternative model reduction methods (such as balanced truncation) and automated modelling frameworks (e.g., linear regression). Further work is required to generalise the results obtained, i.e., by considering different exogenous conditions (e.g., different weather conditions), different comfort periods and different building typologies. This will allow the implementation of the proposed methodology in an ensemble calibration framework, capable of investigating the effect of model reduction in retrofit-decision planning for scenarios such as integrated building-to-grid type analysis.

Author Contributions: Conceptualisation: M.D.R., M.B., and D.P.F. Methodology: M.D.R., M.B., C.A.C., U.E., and D.P.F. Data curation: M.B. and U.E. Formal analysis: M.D.R., M.B., and C.A.C. Writing: M.D.R. and M.B. Editing and revising: M.D.R., U.E., and D.P.F. Project administration: U.E. and D.P.F. Funding acquisition: U.E. and D.P.F. 
Funding: This work emanated from research conducted with the financial support of the European Commission through the H2020 project Sim4Blocks, grant agreement 695965.

Conflicts of Interest: The authors declare no conflict of interest.

\section{Abbreviations}

The following abbreviations are used in this manuscript:

\begin{tabular}{|c|c|}
\hline$a$ & Air \\
\hline att & Attic \\
\hline$b$ & Building \\
\hline$B E M$ & Building energy models \\
\hline C & Thermal capacitance $\left(J K^{-1}\right)$ \\
\hline DHW & Domestic hot water \\
\hline$e$ & External \\
\hline E & Energy (J) \\
\hline$E C$ & Ensemble Calibration \\
\hline EEE & Energy Estimation Error \\
\hline$E F$ & Energy Flexibility \\
\hline est & Estimated \\
\hline$f$ & Fractions \\
\hline$f m$ & Full model \\
\hline$F$ & System matrix \\
\hline G & System matrix \\
\hline gnd & Ground \\
\hline hs & Heating system \\
\hline$H$ & System matrix \\
\hline$i$, int & Internal \\
\hline is & Internal heat source \\
\hline j & Wall index \\
\hline$J$ & Target function \\
\hline$k$ & Index \\
\hline$n$ & Node \\
\hline$N$ & Number of components \\
\hline NH & Horizon length \\
\hline$N Z E B$ & Net-zero energy buildings \\
\hline$p$ & Calibration parameter \\
\hline$P B$ & Physically-based \\
\hline$\Phi$ & Heat source $(W)$ \\
\hline$\dot{q}, Q$ & Heat flow rate $(W)$ \\
\hline$r$ & room \\
\hline$r m$ & reduced model \\
\hline$R$ & Thermal resistance $\left(K W^{-1}\right)$ \\
\hline$R C$ & Resistance-capacitance thermal network \\
\hline RMSE & Root mean square error \\
\hline$s$ & Synthetic/solar \\
\hline$S P$ & Comfort band \\
\hline$T$ & Temperature $\left({ }^{\circ} \mathrm{C}\right)$ \\
\hline$\tau$ & Time (s) \\
\hline$v$ & Ventilation \\
\hline$w$ & Wall \\
\hline win & Windows \\
\hline$x$ & Building model state \\
\hline$z$ & reduced model index \\
\hline
\end{tabular}




\section{References}

1. IEA. Tracking Clean Energy Progress 2017; Technical Report; International Energy Agency: Paris, France, 2017.

2. European Parliament. Directive (EU) 2018/844 of the European Parliament and of the Council of 30 May 2018 amending Directive 2010/31/EU on the energy performance of buildings and Directive 2012/27/EU on energy efficiency. Off. J. Eur. Union 2018, 61, 75-91.

3. European Parliament. Directive 2010/31/EU of the European Parliament and of the Council of 19 May 2010 on the energy performance of buildings. Off. J. Eur. Union 2010, 53, 13-35.

4. Østergaard Jensen, S.; Marszal-Pomianowska, A.; Lollini, R.; Pasut, W.; Knotzer, A.; Engelmann, P.; Stafford, A.; Reynders, G. IEA EBC Annex 67 Energy Flexible Buildings. Energy Build. 2017, 155, $25-34$. [CrossRef]

5. Pallonetto, F.; Mangina, E.; Milano, F.; Finn, D.P. SimApi, a smartgrid co-simulation software platform for benchmarking building control algorithms. SoftwareX 2019, 9, 271-281. [CrossRef]

6. Pallonetto, F.; Mangina, E.; Finn, D.; Wang, F.; Wang, A. A restful API to control a energy plus smart grid-ready residential building: Demo abstract. In Proceedings of the 1st ACM Conference on Embedded Systems for Energy-Efficient Buildings, Memphis, TN, USA, 3-6 November 2014; pp. 180-181.

7. Lund, P.D.; Lindgren, J.; Mikkola, J.; Salpakari, J. Review of energy system flexibility measures to enable high levels of variable renewable electricity. Renew. Sustain. Energy Rev. 2015, 45, 785-807. [CrossRef]

8. Pallonetto, F.; De Rosa, M.; Milano, F.; Finn, D.P. Demand response algorithms for smart-grid ready residential buildings using machine learning models. Appl. Energy 2019, 239, 1265-1282. [CrossRef]

9. De Rosa, M.; Carragher, M.; Finn, D.P. Flexibility assessment of a combined heat-power system (CHP) with energy storage under real-time energy price market framework. Therm. Sci. Eng. Prog. 2018, 8, 426-438. [CrossRef]

10. Paulus, M.; Borggrefe, F. The potential of demand-side management in energy-intensive industries for electricity markets in Germany. Appl. Energy 2011, 88, 432-441. [CrossRef]

11. Kim, J.H.; Shcherbakova, A. Common failures of demand response. Energy 2011, 36, 873-880. [CrossRef]

12. Egan, J.; Finn, D.; Soares, P.H.D.; Baumann, V.A.R.; Aghamolaei, R.; Beagon, P.; Neu, O.; Pallonetto, F.; O'Donnell, J. Definition of a useful minimal-set of accurately-specified input data for Building Energy Performance Simulation. Energy Build. 2018, 165, 172-183. [CrossRef]

13. Davila, C.C.; Reinhart, C.F.; Bemis, J.L. Modeling Boston: A workflow for the efficient generation and maintenance of urban building energy models from existing geospatial datasets. Energy 2016, 117, $237-250$. [CrossRef]

14. Heidarinejad, M.; Mattise, N.; Dahlhausen, M.; Sharma, K.; Benne, K.; Macumber, D.; Brackney, L.; Srebric, J. Demonstration of reduced-order urban scale building energy models. Energy Build. 2017, 156, 17-28. [CrossRef]

15. Kim, E.J.; Plessis, G.; Hubert, J.L.; Roux, J.J. Urban energy simulation: Simplification and reduction of building envelope models. Energy Build. 2014, 84, 193-202. [CrossRef]

16. Good, N.; Zhang, L.; Navarro-Espinosa, A.; Mancarella, P. High resolution modelling of multi-energy domestic demand profiles. Appl. Energy 2015, 137, 193-210. [CrossRef]

17. Zhao, H.X.; Magoulès, F. A review on the prediction of building energy consumption. Renew. Sustain. Energy Rev. 2012, 16, 3586-3592. [CrossRef]

18. Foucquier, A.; Robert, S.; Suard, F.; Stéphan, L.; Jay, A. State of the art in building modelling and energy performances prediction: A review. Renew. Sustain. Energy Rev. 2013, 23, 272-288. [CrossRef]

19. De Rosa, M.; Bianco, V.; Scarpa, F.; Tagliafico, L.A. Heating and cooling building energy demand evaluation; a simplified model and a modified degree days approach. Appl. Energy 2014, 128, 217-229. [CrossRef]

20. Zhou, Q.; Wang, S.; Xu, X.; Xiao, F. A grey-box model of next-day building thermal load prediction for energy-efficient control. Int. J. Energy Res. 2008, 32, 1418-1431. [CrossRef]

21. Berthou, T.; Stabat, P.; Salvazet, R.; Marchio, D. Development and validation of a gray box model to predict thermal behavior of occupied office buildings. Energy Build. 2014, 74, 91-100. [CrossRef]

22. De Rosa, M.; Bianco, V.; Scarpa, F.; Tagliafico, L.A. Impact of wall discretization on the modeling of heating/cooling energy consumption of residential buildings. Energy Effic. 2016, 9, 95-108. [CrossRef]

23. Coakley, D.; Raftery, P.; Keane, M. A review of methods to match building energy simulation models to measured data. Renew. Sustain. Energy Rev. 2014, 37, 123-141. [CrossRef] 
24. Cai, J.; Braun, J. An inverse hygrothermal model for multi-zone buildings. J. Build. Perform. Simul. 2016, 9,510-528. [CrossRef]

25. Joe, J.; Karava, P. Agent-based system identification for control-oriented building models. J. Build. Perform. Simul. 2017, 10, 183-204. [CrossRef]

26. Kim, D.; Braun, J.E. A general approach for generating reduced-order models for large multi-zone buildings. J. Build. Perform. Simul. 2015, 8, 435-448. [CrossRef]

27. Andrade-Cabrera, C.; Burke, D.; Turner, W.J.; Finn, D.P. Ensemble Calibration of lumped parameter retrofit building models using Particle Swarm Optimization. Energy Build. 2017, 155, 513-532. [CrossRef]

28. Ma, J.; Qin, S.J.; Salsbury, T. Model predictive control of building energy systems with balanced model reduction. In Proceedings of the American Control Conference (ACC), Montreal, QC, Canada, 27-29 June 2012; pp. 3681-3686.

29. Deng, K.; Goyal, S.; Barooah, P.; Mehta, P.G. Structure-preserving model reduction of nonlinear building thermal models. Automatica 2014, 50, 1188-1195. [CrossRef]

30. Sim4Blocks. Simulation Supported Real Time Energy Management in Building Blocks. Available online: http:/ / www.sim4blocks.eu (accessed on 20 December 2018).

31. Bianco, V.; De Rosa, M.; Scarpa, F.; Tagliafico, L.A. Analysis of energy demand in residential buildings for different climates by means of dynamic simulation. Int. J. Ambient Energy 2016, 37, 108-120. [CrossRef]

32. Andrade-Cabrera, C.; De Rosa, M.; Kathirgamanathan, A.; Kapetanakis, D.S.; Finn, D.P. A Study on the Trade-off between Energy Forecasting Accuracy and Computational Complexity in Lumped Parameter Building Energy Models. In Proceedings of the IBPSA Conference eSim, Montreal, QC, Canada, 9-10 May 2018.

33. Poli, R. Analysis of the publications on the applications of particle swarm optimisation. J. Artif. Evol. Appl. 2008, 2008, 685175. [CrossRef]

34. Ahmad, M.W.; Mourshed, M.; Yuce, B.; Rezgui, Y. Computational intelligence techniques for HVAC systems: A review. Build. Simul. 2016, 9, 359-398. [CrossRef]

35. Andrade-Cabrera, C.; Turner, W.; Burke, D.; Neu, O.; Finn, D.P. Lumped Parameter Building Model Calibration Using Particle Swarm Optimization. In Proceedings of the 3rd Asia Conference of IBPSA (ASIM 2016), Jeju, Korea, 27-29 November 2016. 